To appear in J. Wyatt, J. Zakkou, and D. Zeeman (eds): Perspectives on Taste. Routledge

\title{
Tastes and the Ontology of Impersonal Perception Reports
}

\author{
Friederike Moltmann
}

October 22, 2021

\begin{abstract}
This paper outlines a novel semantics of sentences about taste ('this tastes good'). This semantics is based on an ontology of taste occurrences and taste objects and does away with implicit experiencers or judges. The semantics generalizes to other impersonal perception reports ('this looks red', 'this sounds good' etc) with their ontology of perceptual occurrences and perceptual objects, including those with agent-centered situations as the objects of perception ('it looks as if it is going to rain').
\end{abstract}

\section{Introduction}

This paper is about what I will call impersonal taste reports as in (1) as well as other impersonal perception reports such as (2):

(1) a. Chocolate tastes good.

b. Chocolate is delicious.

(2) a. The photo looks good.

b. The violin sounds strange.

c. The perfume smells as if it was from Guerlain.

d. It feels as if it is going to rain.

The standard semantic view about such sentences is that the predicates stand for a subjective relation of experience or evaluation between objects and experiencers (judges). This relation is generally used to explain the possibility of faultless disagreement about judgments of personal taste. It underlies standard contextualist and relativist accounts of the semantics of taste sentences, as well as the generic version of the semantics of such sentences proposed in Moltmann (2010a, 2012). 
This paper will argue for a different semantics of impersonal taste reports and impersonal perception reports in general. This semantics is based on a richer ontology of what I will call taste occurrences and taste objects and more generally perceptual occurrences and perceptual objects. Perceptual occurrences involve a particular experiencer and depend on a particular perceptual experience; perceptual objects won't. The proposed semantics will not invoke experiencers or judges as implicit arguments of the perceptual relations expressed by the predicates in (1) and (2), let alone as arguments that are syntactically realized by silent elements (pro). It thus avoids the problems for implicit experiencer arguments pointed out by Collins (2013).

The ontological distinction between perceptual occurrences and perceptual objects is reflected in semantic differences between impersonal perception verbs and the corresponding nouns: impersonal perception verbs (taste, look, sound, smell, feel) take perceptual occurrences as arguments; the corresponding nouns take perceptual objects as arguments. Thus, the verb taste takes a taste occurrence as an implicit argument, whereas the noun taste as in the taste of coffee describes a taste object. Similarly, the nouns in the look of the statue, the sound of the violin, the smell of the perfume, and the feel of the fabric describe perceptual objects.

The ontology of taste occurrences and objective tastes allows dispensing with implicit experiencer arguments. Perceptual occurrences are entities that by nature have an experiencer and in their choice of an experiencer show a particular first-person orientation. More precisely, impersonal perception verbs show a logophoric behavior, which parallels that of generic one: the experiencer is understood either as the speaker, the described attitude bearer, or anyone the speaker or described attitude bearer identifies with or simulates (on the generic reading).

Not just perceptual occurrences have such a first-person orientation, but also the objects of perception themselves may, namely agent-centered situations of the sort sentences like (2d) are about.

In contrast to taste occurrences, taste objects are 'objective' or public and do not involve a particular individual as experiencer. They are not only the sorts of things we refer to explicitly with NPs like the taste of coffee, but are also involved in the semantics of taste adjectives such as delicious or tasty. Given the semantic involvement of taste objects, faultless disagreement of sentences such as (1b) resides in the first-person based evaluation of a taste object, rather than the perceptual experience itself. 
The paper will first briefly present standard semantic views of sentences about personal taste and address semantic differences between impersonal perception verbs and corresponding nouns and adjectives. It will then outline the ontology of perceptual occurrences and perceptual objects as well the semantics of impersonal perception reports with the two sorts of predicates. At the end, it will address the sorts of predictions the present approach makes regarding faultless agreement.

\section{Standard semantics of sentences expressing personal taste}

The general assumption is that taste predicates express a subjective, experiential relation that holds between an object (or kind of object) and an agent a, the experiencer or 'judge', so that (3a) has the logical form in $(3 b):^{1}$

(3) a. Coffee tastes good.

b. tastes good(coffee, a)

Doubts whether such simple contextualist or relativist analyses can explain the phenomenon of faultless disagreement have motivated a more complex analysis of (3a) in terms of firstperson-based genericity, involving simulation (Moltmann 2010a, 2012). A simplified version of that analysis is given for (3a) below, for Gn being a suitable generic operator:

(4) a. Everyone as someone the speaker identifies with has a good-tasting experience of coffee.

b. $\lambda x[\mathrm{Gn} y$ taste good to(coffee, $\mathrm{y}$ qua someone $\mathrm{x}$ identifies with $\mathrm{y})]$

Thus, (4a) expresses a property, a property which needs to be self-applied by anyone accepting the content of the sentences.

Support for the involvement of genericity in taste statements such as (1a) comes from the possibility of co-variation of the 'judge' with generic one or arbitrary PRO, as in (5a) and (5b) respectively:

\footnotetext{
${ }^{1}$ There is another view on which the experiencer or judge is part of the context of assessment, requiring reassessment by anyone evaluating the sentences as true or false (McFarlane 2014, Lasersohn 2005). Then, tasty denotes a property of objects, with judges acting as parameters of evaluation besides $\mathrm{s}$, as below:

(i) $[\operatorname{tasty}(\text { coffee })]^{\mathrm{w}, \mathrm{t}, \mathrm{a}}=$ true iff coffee is tasty to a in $\mathrm{w}$ at t
} 
(5) a. When one drinks milk cold, it tastes pro good.

b. It is pleasant pro $\mathrm{PRO}_{\text {arb }}$ to sit on the sofa.

In what follows, I will assume that taste sentences such as (3a) display both a generic reading, along the lines of (4b), as well as a first-person-oriented non-generic reading on which the speaker (or described agent) just conveys her own taste judgment. The latter, given the standard assumption about taste predicates and a standard, Lewisian account of de se, would be represented as below:

(4) c. $\lambda x[$ tastes $\operatorname{good}($ coffee, $x)]$.

\section{Verbal, adjectival, and nominal taste predicates}

\subsection{An individual level- stage level distinction among taste predicates}

Judgments of taste take different linguistic forms, which go along with somewhat different readings. In particular, verbal taste predicates as in (6a) display different readings from adjectival taste predicates as in (6b):

(6) a. The coffee tastes delicious.

b. The coffee is tasty.

Pearson (this volume) points out that complex taste predicates as in (6a) permit both a generic reading and two sorts of non-generic readings, namely a first-person referential reading and bound-variable readings. This, for Pearson, is due to the fact that complex taste predicates are 'stage-level'. By contrast, simple taste predicates display only a generic reading, which for Pearson means that they are 'individual-level'.

Pearson lists various manifestations of the individual-level/stage-level distinction among taste predicates. ${ }^{2}$ One of them are the readings of the floated all, which with complex taste

\footnotetext{
${ }^{2}$ Pearson also lists the possibility of adverbial modifiers with stage-level predicates but not with individual-level predicates, using the following examples:

(i) a. This tea tastes good in a China cup. b. ??? This tea is tasty in a China cup.
} 
predicates gets a reading on which it ranges over situations, as in (7a) but with simple taste predicates it only has a reading on which it ranges over the relevant individuals, as in (7b ):

(7) a. Pineapples always taste good.

b. Pineapples are always tasty.

The same contrast holds for other impersonal perception verbs and the corresponding adjectives. In (8a), always ranges over situations (broadly speaking, including times of the day), in (8b) always can range only over churches:

(8) a. English churches look always beautiful;

b. English churches are always beautiful.

Another diagnostics is the acceptability of when-clauses:

(9) a. When the landscape looks beautiful, people photograph it.

b. ?? When the landscape is beautiful, people photograph it.

Stage-level predicates can occur in a when-clause, but not individual-level predicates.

Yet another diagnostics is the ability for stage-level predicates to occur as small-clause predicates of see, as opposed to individual-level predicates:

(9') a. Emma saw St Paul's looking beautiful.

b. ??? Emma saw St Paul's beautiful.

For Pearson, simple taste predicates being 'individual level' means that they are always generic, involving a generic operator with just scope over the predicate at logical form (Chierchia 1995). Thus, whereas (10a) has a first-person referential reading as in (10b) as well as a generic reading involving a wide-scope generic operator as in (10c), (11a) requires a generic operator taking scope just over the predicate as in (11b):

(ii) a. St Pauls' looks beautiful today.

b. ??? St Paul's is beautiful today.

However, it appears that speakers do not generally agree with the judgments. 
(10) a. This cake tastes good.

b. $\mathrm{Gn}_{\mathrm{i}}$ [this cake tastes good (to) $\left.\mathrm{pro}_{i}\right]$

c. [tastes good (to)](this cake, speaker)

(11) a. This cake is tasty.

b. This cake $\left[\mathrm{Gn}_{\mathrm{i}}\left[\right.\right.$ is tasty pro $\left.\left._{i}\right]\right]$

c. For any entity d, $\left[\mathrm{Gn}_{\mathrm{i}}\left[\right.\right.$ is tasty $\left.\operatorname{pro}_{i}\right](\mathrm{d})=1$ iff $\mathrm{x}$ is tasty to everyone in any (relevant) situation.

There are several issues, however, that arise for this account of simple and complex taste predicates.

First of all, the account does not give a compositional semantics of complex taste predicates like taste good and in particular fails to give justice to the contribution of the secondary predicate good in such predicates. In fact, the distinction between complex and simple predicates does not align well with the individual-level - stage-level distinction. Complex predicates with taste nouns such as has a bitter taste classify as individual-level, not stage-level.(Section 4.1.)

Second, the account does not explain the stage-level/individual-level correlation with the two sorts of predicates. The simple predicates she considers are all adjectives, but adjectives themselves are not generally individual-level. Available, apparent, unwell, happy are stagelevel, for example. There are also adjectives that can be used for taste judgments that fail to be individual-level, for example terrible and stimulating, predicates that focus on the effect on the experiencer. Such adjectives pattern with stage-level predicates given the various diagnostics, as indicated below:

(12) a. When I drank it at room temperature, the wine was terrible.

b. When I drink coffee in the morning, it is stimulating; when I drink it at night it puts me to sleep.

Third, the account fails to carry over to the semantics of taste nouns and other nouns denoting perceptual objects: the taste of coffee, the look of St Paul's, the smell of the perfume, the sound of the violin display only a sort of generic reading, not a reading relating to a particular perceptual occurrence. In the next section, we will discuss in greater the nominal construction, whose semantics can also shed light on the first and second issue with Pearson's account. 
Fourth, the account hinges on treating taste predicates in impersonal taste reports as involving an experiencer argument, syntactically realized by a silent element pro. However, there is little if any syntactic evidence for judge or experiencer arguments of predicates in impersonal taste sentences, as Collins (2013) has argued in relation to criteria such as variable binding, obligatory arguments, and ellipsis. This also holds for other predicates of perception in impersonal perception reports.

Finally, Pearson's account fails to capture the first-person orientation or logophoric character of impersonal perception verbs, an issue I will turn to now.

\subsection{The logophoric nature of verbal taste predicates}

Verbal taste predicates differ from adjectival ones not only in their stage-level as opposed to individual-level behavior, but also in displaying a particular first-person-orientation or logophoric character. Pearson (this volume) notices that a first-person covert indexical reading is available for verbal taste predicates as in (13a), but not adjectival ones as in (13b), an observation that generalizes to all impersonal perception verbs, as in (14):

(13) a. When I am hungry, beans taste good.

b. ?? When I am hungry, beans are tasty.

(14) a. When put in a long vase, a single rose looks nice.

b. ?? When put in a long vase, a single rose is nice-looking.

A related observation is that a first-person bound-variable reading with generic one as antecedent is available only with verbal taste predicates and not adjectival ones:

(15) a. When one is hungry, beans taste good.

b. ?? When one is hungry, beans are tasty.

Impersonal perception verbs need not relate to the speaker, though. In contexts embedded under attitude verbs, they will relate to whoever is the described agent. They may do so displaying a referential reading (16a) or bound variable reading (16b):

(16) a. John found that the cake tasted good.

b. Everyone who ordered wine was upset that the wine did not taste good. 
Taste occurrences still relate to the speaker when the taste predicate is not embedded under an attitude verb, as in (17):

(17) Everyone is drinking wine that tastes good.

The same generalization holds for impersonal perception verbs of other perceptual modes, illustrated by the following contrast:

(18) a. Everyone who looked at the picture from the entrance was angry that the picture did not look good.

b. Everyone stood next to a picture that did not look good.

With respect to the perceptual occurrences they describe, impersonal perception verbs thus behave like logophoric pronouns, and also generic one, in relating to the speaker or else whoever is the bearer of the relevant described attitude,. Impersonal perception verbs differ in that respect from ordinary perception verbs (see, hear etc), which fail to display such logophoricity. Capturing the latter is an important condition for an adequate semantics of impersonal perception verbs.

\section{Taste occurrences and other perceptual occurrences}

\subsection{The linguistic form of impersonal verbal perceptual reports}

On the present view, taste verbs denote relations between entities and taste occurrences, and adjectival taste predicates relations between entities and taste objects. Neither involves experiencers as arguments. That is because the ontology of taste objects and other perceptual objects permits dispensing with experiencer arguments. Perceptual occurrences are dependent on or directed toward a particular experiencer. If impersonal verbs of perception denote relations between entities and perceptual occurrences, they won't require experiencer arguments for semantic reasons. By contrast, perceptual objects do not depend on particular experiencers. If adjectival taste predicates denote relations between entities and taste objects, an obligatory generic reading of adjectival predicates will follow without making use of experiencers. 
If impersonal perception predicates denote relations between entities and perceptual occurrences or perceptual objects, such as tastes, looks, sounds, and smells, this permits a compositional semantics of complex predicates such as taste good or look nice. But first a few remarks are in order about such predicates.

Impersonal perceptual reports with a verbal predicate are of the form DP V XP, where V is an impersonal perception verb (look, sound, smell) and XP an obligatory adverbial modifier or secondary predicate. Though obligatory, the secondary predicate occupies the very same position as other adverbial modifiers. The secondary predicate can be any expression that can also act as an adverbial. On the present view, it always expresses a property to be predicated of the perceptual occurrence. Impersonal perception reports then will involve existential quantification over perceptual occurrences and predication of the secondary predicate of the perceptual occurrences. For an impersonal taste report such as (19a) this is given in (19b):

(19) a. The cake tastes good.

b. $\exists \mathrm{d}(\operatorname{taste}($ the cake, d) \& $\operatorname{good}(\mathrm{d}))$

In (19b), no use was made of event arguments. That is because the issue of event arguments is rather independent of the argument in favor of perceptual occurrences and perceptual objects.

The sort of analysis in (19b) will also be the semantics impersonal perceptual reports of other perceptual modes.

The generic reading of verbal impersonal perceptual reports does not involve a distinct entity, but rather a generic operator, which one may assume, ranges just over situations suitably restricted. Thus, on the generic reading, the logical form of (19a) will be:

(19) c. Gn s $\exists d\left(\operatorname{taste}_{\mathrm{s}}\left(\right.\right.$ the cake, d) \& $\left.\operatorname{good}_{\mathrm{s}}(\mathrm{d})\right)$

There is an issue whether generically quantified sentences of this sort require actual instances. The potential truth of sentences like (20) indicates that they don't (McGrawth p.c.): ${ }^{3}$

(20) I'm sure the garden looks beautiful today, since it's such a nice day, so it's a shame they've closed off the place to all visitors, so that no one can see it.

\footnotetext{
${ }^{3}$ But see Dinges/Zakkou (2020) for arguments that they do.
} 
The distinction between perceptual occurrences and perceptual objects is of course compatible with the generic operator not requiring actual instances.

(19a) actually has two readings (Jackson 1977, Rudolph, this volume): a phenomenal reading on which good applies to the appearance, the taste occurrence, and a non-phenomenal reading on which it applies to the stimulus. On the second reading, the taste occurrence indicates that the cake is good, ratherthan qualifying the taste as such. I will not discuss the second reading in greater detail in this paper, but just suggest an ontological account of the two readings. Whereas on the first reading, the secondary predicate applies to the taste occurrence itself, on the second reading it applies to the epistemic modal object generated by the taste occurrence. ${ }^{4}$ Unlike a taste occurrence, a modal object has truth or satisfactions, and their content may include the content of various sentences (or small clauses). The modal object generated by a taste object d then supports the small clause [the cake good] (that is, the content of [the cake good] is part of the content of $\mathrm{m}$ ) just in case $\mathrm{d}$ is evidence for the truth of [the cake good]. Given this proposal, the ambiguity between the phenomenal and the nonphenomenal reading is traced to the semantics of impersonal perception verbs, more precisely, the ontology that goes along with them, that is, the ontology of perceptual occurrences and the modal objects they generate.

The secondary predicate of impersonal perception reports may also be an as if-clause, an as though-clause or a like-clause, which generally can fill in the position of optional as well as selected adverbials: ${ }^{5}$

(21) a. John walks as if he was drunk.

b. John behaves like he was being hunted.

(22) a. This looks / tastes / smells / sounds as though it was very old.

b. The landscape looks like it had not rained for weeks.

\footnotetext{
${ }^{4}$ For more on modal objects see Moltmann $(2017,2018)$, where modal objects are taken to have a truthmakerbased content. Modal objects have been taken to play a central role in the semantics of modal sentences within truthmaker semantics, more precisely object-based truthmaker semantics.

${ }^{5}$ As if-clauses also permit co-variation of generic one with the experiencer of the described perceptual occurrences:
}

(i) The massage feels as if one was being tortured. 
The semantics of as if-clauses and like-clauses is more complex of course (see Bledin/Srinivas to appear for a recent discussion and possible-worlds-based analysis). The ontology of perceptual occurrences promises a new analysis along the following lines, where $\mathrm{X}$ is a definite NP and $\mathrm{f}$ is a function mapping the set $[\mathrm{S}]$ of situations described by the sentence $\mathrm{S}$ to a matching kind of perceptual occurrences:

(23) a. X looks as if S.

b. For a perceptual occurrence $d, \operatorname{look}([\mathrm{X}], \mathrm{d})$ and $\mathrm{d}$ is similar to the kind of perceptual occurrence that matches the situational content of $\mathrm{S}$.

c. $\exists \mathrm{d}(\operatorname{look}([\mathrm{X}], \mathrm{d}) \& \mathrm{~d} \sim \mathrm{f}([\mathrm{S}],[\mathrm{X}]$, look $)$

How the relation of a set of situation to a kind of perceptual occurrences is to be understood needs to be elaborated, of course. But, as it is marginal to the main theme of this paper, this can be left for another occasion. Note that (23b) captures only the non-generic reading of (23a). The generic reading arguably does not require there to be an actual perceptual occurrence. $^{6}$

\subsection{The nature of taste occurrences}

Taste occurrences are concrete qualities borne by taste experiences. Taste occurrences are thus dependent on the experience and its experiencer. The identity and existence of taste occurrences obviously depends on the agent. If I did not taste the coffee, the coffee did not taste good to me. The properties of taste occurrences are different though from the experience itself. The experience, for example, has temporal properties, but the taste occurrence won't. A taste experience can occur unintentionally or by mistake, but this is not what one would attribute to the taste occurrence. The taste occurrence only has qualitative properties, such as being sour, bitter, or sweet, which one would not attribute to the taste experience itself.

It is not obvious how exactly the relation between a taste occurrence and a taste experience should be conceived, and how their relation should possibly be reflected in the semantics of impersonal taste sentences. The relation might possibly be conceived as one

\footnotetext{
${ }^{6}$ Thus, McGrath (p.c.) points out the potential truth of (i), when the speaker knows that no one is looking at the house now:
}

(i) I wonder if his house still looks as if it is about to fall down, which it did last time I saw it. 
between and event and its result, as is suggested by German resultative morphology for taste occurrences (schmecken - to taste, Geschmack - taste). ${ }^{7}$ In this paper, I will set aside taste experiences and take impersonal taste predicates to only take a taste occurrence as an argument.

Other perceptual modes likewise come with perceptual occurrences besides perceptual experiences. Subjective looks are qualities borne by visual experiences, sound occurrences are qualities borne by auditory experiences, smell occurrences are qualities borne by olfactory experiences. Again, the properties of the occurrences are obviously different from those of the experiences.

(20) does not yet capture all there is to the semantics of impersonal perception verbs. In particular, it does not account for [1] the logophoric character of impersonal perception verbs and [2] the possibility of generic readings, and in particular covariation with generic one.

Impersonal perception verbs describe perceptual occurrences that relate either to the speaker or in contexts embedded under attitude verbs, the attitude bearer. It thus relates to a context that is centered on an intentional agent and can be shifted under embedding under attitude verbs. In this paper, I will make use only of very basic, familiar tools of semantic analysis, leaving a possibly more accurate semantic analysis of the phenomenon to a future occasion. I will assume that sentences are evaluated with respect to two contexts: a context $u$, the utterance context, and a context $\mathrm{c}$, the context of evaluation that may be shifted for sentences embedded under attitude verbs. Both contexts, for present purposes, are identified with a triple consisting of a situation or world $\mathrm{s}$, a time $\mathrm{t}$, and an agent a. Thus, for a context $\mathrm{c} \mathrm{s}_{\mathrm{c}}$ will be the situation in $\mathrm{c}, \mathrm{t}_{\mathrm{c}}$ the time in $\mathrm{c}$, and $\mathrm{a}_{\mathrm{c}}$ the agent in $\mathrm{c}$. Attitude reports shift the context $\mathrm{c}$ to one in which the agent is the described attitude holder, as indicated below for believe, making use, for present purposes, of a Hintikka-style semantics of belief reports:

(24) For contexts $u$ and c, and an individual a',

[believe that $\mathrm{S}]^{\mathrm{u}, \mathrm{c}}\left(\mathrm{a}^{\prime}\right)=1$ iff for all s', $\mathrm{s}^{\prime} \mathrm{R}_{\text {believe,ac }} \mathrm{S}_{\mathrm{c}}[\mathrm{S}]^{\mathrm{u}, \mathrm{c}^{\prime}}=1$, where $\mathrm{c}^{\prime}$ is like c except that $\mathrm{s}_{\mathrm{c}}=\mathrm{s}^{\prime}$ and $\mathrm{a}_{\mathrm{c}}=\mathrm{a}^{\prime}$.

\footnotetext{
${ }^{7}$ If taste occurrences are regarded as results of taste experiences, this would match the view that judgments are results of acts of judging and conclusions results of acts of concluding (Moltmann 2017). Given such a view, the logical form of (19a) would be as below:

(i) $\exists e($ taste $(e$, the coffee $) \&$ good(result(the coffee $)))$
} 
Let us take $\mathrm{H}$ to be the relation of 'having' or bearerhood that holds between an agent and a perceptual occurrence. Then impersonal perception verbs will be subject to the following condition:

(25) Logophoric condition on impersonal perception verbs

For an impersonal verb of perception $\mathrm{V}$, for contexts u and c, $[\mathrm{V}]^{\mathrm{u}, \mathrm{c}}=\left\{\mathrm{x} \mid \exists \mathrm{d}\left(\left\langle\mathrm{x}, \mathrm{d}>\in[\mathrm{V}]^{\mathrm{u}, \mathrm{c}} \& \mathrm{H}\left(\mathrm{d}, \mathrm{a}_{\mathrm{c}}\right)\right)\right\}\right.$

(19a) will now have the truth conditions below:

(26) $[\text { the cake taste good }]^{\mathrm{u}, \mathrm{c}}=1$ iff $\exists \mathrm{d}\left(\left([\text { the cake }]^{\mathrm{u}, \mathrm{c}}, \mathrm{d}\right) \in\left[\right.\right.$ tastes $^{\mathrm{u}, \mathrm{c}} \& \mathrm{H}\left(\mathrm{d}, \mathrm{a}_{\mathrm{c}}\right) \&$ $\left.\mathrm{d} \in[\text { good }]^{\mathrm{u}, \mathrm{c}}\right)$

Let us then turn to the generic reading of impersonal perception reports as well as the semantics of generic one. I will assume that on the generic reading, impersonal perception reports will involve a generic operator $\mathrm{Gn}$ which will shift not only the situation $\mathrm{s}_{\mathrm{c}}$ of the context of evaluation $\mathrm{c}$, but also the agent $\mathrm{a}_{\mathrm{c}}$ in $\mathrm{c}$, as below, where $\mathrm{R}$ is a suitable relation restricting the situations of evaluation:

(27) The generic reading of impersonal perception reports

For an impersonal perception verb V, a definite NP Y, and a modifier X,

$[\mathrm{Gn} \mathrm{Y} \mathrm{V} \mathrm{X}]^{\mathrm{u}, \mathrm{c}}=1$ iff for all situations s' and individuals a such that s' $\mathrm{R} \mathrm{s}_{\mathrm{c}}$, there is a perceptual occurrence $d$ such that $\langle[Y], d\rangle \in[V]^{\mathrm{u}, \mathrm{c}^{\prime}} \& \mathrm{~d} \in[\mathrm{X}]^{\mathrm{u}, \mathrm{c}^{\prime}}$, where $\mathrm{c}^{\prime}$ is like c, except that $\mathrm{s}_{\mathrm{c}}=\mathrm{s}^{\prime}$ and $\mathrm{a}_{\mathrm{c}}=$ the agent in $\mathrm{s}^{\prime}$.

Generic one involves the same type of logophoricity as impersonal perception verbs, which means that generic-one sentences will relate to the gent of the shiftable context c. On my previous account (Moltmann 2006, 2010b), generic one ranges over individuals (in the relevant group) qua individuals the speaker identifies with or simulates. For present purposes, I will adopt that account, but in addition I will assume that generic one goes along with a change in the context $\mathrm{c}$, shifting the speaker (or attitude bearer) in $\mathrm{c}$ to the individuals generic one ranges over: 


\section{(28) The semantics of generic one}

$[\text { one } \mathrm{VP}]^{\mathrm{u}, \mathrm{c}}=1$ iff for all a', a' $\left[\right.$ qua $\left.\mathrm{a}_{\mathrm{c}} \mathrm{I} \mathrm{a}^{\prime}\right] \in[\mathrm{VP}]^{\mathrm{u}, \mathrm{c}^{\prime}}$, where $\mathrm{c}^{\prime}$ is like c except that $\mathrm{a}_{\mathrm{c}^{\prime}}=\mathrm{a}^{\prime}$.

Here I is the relation of identification or simulation, which ensures that with generic one a predicate is applied to an individual a' on the basis of the speaker putting herself into the shoes of a' - or simulating a' (Moltmann 2006, 2010b).

Covariation of generic one with the experiencer associated with an impersonal perception verb is made possible through the presence of a single generic operator in the sentence, an operator that will trigger a shift of the context c to contexts c' such that the agents of the contexts c' are the individuals the generic operator ranges over. This is indicated for conditionals below (using a very simplified semantics):

(29) For contexts u and c, a definite NP Y, an impersonal perception verb V, and a modifier $\mathrm{X}$,

[If one $\mathrm{VP}$, then $\mathrm{Y} \mathrm{V} \mathrm{X}]^{\mathrm{u}, \mathrm{c}}=1$ iff: for all a', if a' [qua $\left.\mathrm{a}_{\mathrm{c}} \mathrm{I} \mathrm{a}^{\prime}\right] \in[\mathrm{VP}]^{\mathrm{u}, \mathrm{c}^{\prime}}$, then $\exists \mathrm{d}\left(\langle[\mathrm{Y}], \mathrm{d}\rangle \in[\mathrm{V}]^{\mathrm{u}, \mathrm{c}^{\prime}} \& \mathrm{~d} \in[\mathrm{X}]^{\mathrm{u}, \mathrm{c}^{\prime}}\right)$, where is $\mathrm{c}^{\prime}$ is like c except that $\mathrm{a}_{\mathrm{c}^{\prime}}=\mathrm{a}$.

The same analyses apply to impersonal perception verbs of other modes. The sentences below will be about visual, auditory; olfactory; and tactile occurrences with the same first personal orientation or logophoric status as the taste occurrences described by the verb taste:

(30) a. When I saw the picture this morning, it looked great.

b. When I listened to it this morning, the piano sounded good.

c. When I touched the fabric this morning, it felt good.

Impersonal verbs of perception thus describe simple relations between entities and perceptual occurrences, and it is their logophoric status that restrict those perceptual occurrences to those whose experiencers are the 'agents' of the current contexts of evaluation.

\section{Taste objects and other perceptual objects}

\subsection{Taste nouns and nouns for other perceptual objects}


The noun taste enables reference to a taste object, an entity that is independent of particular taste experiences and in particular does not depend on a particular experiencer. Nominal taste predicates in the constructions below share the same apparent generic reading of adjectival taste predicates, as opposed to verbal predicates. That is, (29a) and (29b) only have the reading of $(29 \mathrm{c})$, not of $(29 \mathrm{~d})$ :

(29) a. The coffee has a good taste.

b. The taste of the coffee is good.

c. The coffee is tasty.

d. The coffee tastes good.

The application of relevant diagnostics supports that, for example the acceptability of whenclause:

(30) a. When I am really hungry, plain rice tastes good.

b. ?? When I am really hungry, plain rice is tasty.

c. ?? When I am really hunry, the taste of plain rice is good.

The nominal constructions displays a reading on which good does not evaluate a particular tasting experience or rather taste occurrence, but the taste of the coffee / plain rice as something objectual or public. This is obvious from the way epistemic predicates apply. The taste of coffee is treated an object of knowledge, recognition, and differentiation:

(31) a. Mary knows the taste of coffee.

b. Bill recognizes the taste of cigarettes.

c. Bill cannot distinguish the taste of coffee from the taste of chocolate.

Similarly, there are nouns for objects of other perceptual modes, such as looks, sounds, smells, which also provide objects of knowledge:

(32) John knows the look / sound / smell of cats. 
Apart from the semantics of nouns for perceptual objects and of impersonal perception reports, looks as entities have been motivated for purely philosophical reasons as well, namely for perceptual justification. Entities that are looks, McGrath $(2017,2018)$ has argued, act as the reasons for perceptual beliefs

There are actually two uses of nouns for tastes and other perceptual objects that need to be distinguished: a relational use and a nonrelational use. The relational use is restricted to reference to taste objects, as in (33a), whereas the non-relational use serves for reference to taste occurrences and kinds of them, as in $(33 \mathrm{~b}, \mathrm{c}):^{8}$

(33) a. I know the taste of coffee.

b. I don't know this taste.

c. I have never experienced this taste.

Only the construction the taste of applies to an entity mapping it to the 'objective' taste object that is associated with it.

For a given entity there may not be single perceptual object for a particular perceptual mode, but rather a distinction may have to be made between viewpoint-relative looks and what I will call 'overall looks' ('looks in the round') (McGrath 2021). The relational noun look can be used for both, (34a) and (34b) illustrate:

(34) a. The statue has different looks, depending on the light and where one stands.

b. I like the look of the statue.

With nominal taste predicates, it depends on the nature of the property expressed by the adjective whether faultless agreement arises: evaluative predicates like good give rise to faultless agreement, as is possible in (35); predicates like bitter as in (36) don't, an issue I will come back to in Section 6:

(35) a. Coffee has a good taste.

\footnotetext{
${ }^{8}$ A similar distinction holds for the noun color (Moltmann 2013). (ia) has a reading involving reference to kinds of color occurrences, which is unavailable in (ib):

(i) a. I have never seen this color.

b. ? I have never seen the color of this car.

In (ib) color of is used relationally, referring to the color that pertains to a particular object.
} 
b. The taste of coffee is good.

(36) a. Coffee has a bitter taste.

b. The taste of the coffee is bitter.

In this paper, I will not give a full ontological account of taste objects and other perceptual objects. Rather it will have to suffice to characterize them in terms of some of their linguistically reflected properties. ${ }^{9}$ First of all, tastes are ontologically dependent on an entity, and thus they cannot be conceived as properties. But tastes might be conceived as particularized properties, more precisely, particularized response-dependent properties. The entities on which a taste depends may inherit properties from the taste. Coffee is bitter because its taste is bitter, for example. But this does not hold for all properties. The taste of the wine may be unusual while the wine is not unusual. Objective tastes are to be distinguished from tastes that pertain to particular taste experiences, that is, 'taste occurrences'. A taste object might be construed as a kind of taste occurrence, that is, a kind whose instances are particular taste occurrences. However, taste objects do not appear to require actual instances, an intuition that is even clearer with related entities such as looks, as we will see.

\subsection{The semantics of nominal and adjectival taste predicates}

Tastes as entities and the distinction between taste occurrences and taste objects allow for a straightforward semantics of verbal and nominal taste predicates. Verbs like taste take particular taste occurrences as arguments, whereas the relational noun taste (of) takes taste objects as arguments. Thus the logical form of (37a) will be as in (37b), where the relational noun taste is taken to denote a function from entities to taste objects:

(37) a. The taste of the coffee is good.

b. good(taste(the coffee))

The individual-level status of taste adjective such as tasty can now be attributed to the implicit presence of taste objects, along the lines of the following equivalence:

\footnotetext{
${ }^{9}$ In fact, a semanticist should not have to decide how tastes are to be conceived ultimately, this rather is a matter for the philosopher of mind or metaphysician to decide. See the discussion of the distinction between foundational and naïve or descriptive metaphysics (which comprises natural language ontology) in Fine (2017) and Moltmann (2019).
} 
(38) tasty(the coffee) iff good(taste(the coffee))

This carries over to other perceptual relational nouns (smell, sound, feel) and perceptual adjectives.

The distinction between taste occurrences and taste objects generalizes to other modes of perception, though with different extents to which the objects are experience-dependent. With sounds, the distinction between experience-dependence and object-dependence is particularly intuitive. One may hear a particular sound and one may hear / know / recognize the sound of a particular flute. Verbal taste predicates display an experience-dependent reading, as in (39a); relational uses of nouns display an object-dependent reading, as in (39a, b):

(39) a. This flute sounds unusual.

b. This flute has an unusual sound.

c. The sound of the flute is unusual.

The sound of a flute clearly is independent of a particular experience. It is less obvious that sounds are dependent on the object that produces them. Intuitively, the very same sound could have been produced by a different flute. Moreover, objects on which sounds depend do not generally inherit properties from the sounds. Thus, evaluative predicates when applied to musical instruments generally evaluate their physical shape, not their sounds. Deep cannot be applied to a contrabass even if the sound of it is deep, and deep applies to voices, not to the people that make the sounds.

Both predicates give rise to faultless disagreement with evaluative adjectives (See Section $6)$ :

(40) a. This flute sounds nice.

b. This flute has a nice sound.

c. The sound of the flute is nice.

Smells display the very same pattern, allowing for verbal and nominal predicates, as in (41), and displaying faultless disagreement with evaluative predicates, as in (42) (Section 6): 
(41) a. The perfume smells fruity.

b. The perfume has a fruity smell.

(42) a. The perfume smells nice.

b. The perfume has a nice smell.

Properties of smells are inherited by entities only if the entities are of the very same nature (perfumes). Whereas properties of looks (properties of shape, size) are inherited from the entities that have the looks, properties of sounds, smells, tastes are not inherited from the entities that have them.

\subsection{The ontology of perceptual objects}

What is the ontological status of perceptual objects? Do they depend on experiences or are they mind-independent? McGrath $(2017,2021)$, who argued that looks play a role both in perceptual justification and in the semantics of looks reports, argues against subjectivist and dispositionalist accounts of looks. First of all, looks do not require experiences by agents; they are 'public' entities. This holds both for viewpoint-relative looks and overall looks. ${ }^{10}$ Linguistically, this reflected in the acceptability of the sentences below:

(43) a. The statue would look the same even if no one had looked at it.

b. The statue would have the same looks from the different angles even if no one had looked at it.

McGrath also argues against dispositionalist accounts of looks for ontological reasons: we do not 'see' or 'recognize' dispositions when we see or recognize a look. Ontologically, McGrath (2018) proposes to identify sets of sensible properties. An alternative that one might pursue is to take them to be kinds of (collections of) response-dependent tropes. Both views, though, still have to elaborate the distinction between view-point-relative and overall looks. ${ }^{11}$

\footnotetext{
${ }^{10}$ McGrath (2018) distinguishes those from 'subjective looks', which would fall under perceptual occurrences in the present sense.

${ }^{11}$ McGrath (2021) proposes that view-point-relative looks: be conceived as properties of presenting light of a certain character to the viewpoint, where looks on the round (overall looks) are what it is about an object that grounds the possibilities of its viewpoint-relative looks. This account obviously does not carry over to perceptual objects of other perceptual modes.
} 
To what extent can the arguments for experience-independence be generalized to perceptual objects of other modes? The contrasts below indicate that they apply also to taste objects, as opposed to taste occurrences, at least with non-evaluative predicates:

(44) a. ? If one can no longer drink coffee, coffee can no longer taste bitter.

b. If one can no longer drink coffee, coffee would still have a bitter taste.

(45) a. ? If one can no longer drink coffee, coffee can no longer taste good.

b. (?) If one can no longer drink coffee, coffee would still have a good taste.

The arguments do not carry over to all perceptual objects, though, in particular not those that can hardly be separated from the experience itself, such as physical and emotional feelings (as in the massage feels great, the praise felt good). ${ }^{12}$ Feelings come with verbal predicates describing occurrences as well as nominal predicates describing feelings as objectual, 'public' entities. The latter, again, are able to act as objects of knowledge:

(46) a. I don't know what it feels like to be praised by everyone.

b. I know the pleasure of good company.

That 'feelings' can hardly be dissociated from the experiences appears to be reflected linguistically, namely in the choice of the light verb with the nominal construction. Whereas tastes, looks, smells, and sounds are selected by the light verb have, feelings are selected by the light verb give:

(47) a. This thing has / ?? gives a nice taste / look / smell / sound.

b. The massage gives / ??? has a strange feeling.

Thus, at least some perceptual objects are individuated on the basis of experiences themselves.

\section{Implicit agent-centered situations as objects of perception}

\footnotetext{
12 Feeling of this sort need to be distinguished from tactile feels, which are as experience-independent as tastes, looks and sounds:

(i) a. The fabric feels rough

b. The feel of the fabric is rough.
} 
Not only individuals or kinds of them may serve as referents of the subject of impersonal perceptual reports. The very same types of impersonal perception reports allow for what I will call agent-centered situations as the objects of perception. These are perceptual reports with the pronoun it as apparent expletive or dummy subject: ${ }^{13}$

(48) a. It is nice / hot / dark here.

b. It smells nice here.

(49) a. It looks like it is going to rain.

b. It sounds like there will be a tempest.

c. It smells like there is a fire nearby.

d. It felt as if it was going to rain.

In (48a, b), here obviously gives the speaker's location. Other location modifiers are possible only if they specify the location of the speaker (or described attitude bearer) at another time as in $(50 \mathrm{a}, \mathrm{b})$ and $(51)$ or if the sentence has a generic reading, as in $(52)::^{14}, 15$

(50) a. It was nice in Germany.

b. It will be interesting in Beijing.

(51) There it looked like it was going to rain.

(52) It is pleasant in Paris in spring.

\footnotetext{
${ }^{13}$ Not all perception verbs that can occur in impersonal perception reports allow for agent-centered situations. German wirken 'appear', for example, cannot:

(i) a. Hans wirkt muede. 'Hans appears tired.'

b. Hans wirkt, als haette er nicht geschlafen. 'John appears as if he had not slept.'

c. * Es wirkt, als wuerde es regnen. 'It appears as if it was going to rain.'

${ }^{14}$ Sentences reporting weather (it is raining) belong to the same syntactic class; though they are less directly related to perception.

${ }^{15}$ (50a), (50b) and (51) also have a generic reading on which they do not require the speaker's (or anyone's) presence at the location in question.
} 
With agent-centered situations, the copula be can take the place of the perception verb, as in the first stanza of the most famous German romantic poem:

(53) Es war, als hätt' der Himmel die Erde still geküßt, daß sie im Blütenschimmer von ihm nun träumen müßt'. (Josef von Eichendorff Mondnacht 'Moonlight')

'It was as though Heaven had softly kissed the Earth, so that she in a gleam of blossom had only to dream of him. (translation Richard Stokes)

The agent-centered situations appear to have the very same 'logophoric' status as the perceptual occurrences of impersonal perception verbs. In contexts embedded under attitude verbs with a different agent, the situation will be centered on the other agent, as in (54a); but such a shift is not available without attitude verb, as in (54b), where pleasant can relate only to the speaker:

(54) a. John was happy that it was so pleasant in Germany.

b. John met me while it was still so pleasant in Berlin.

Agent-centered situations may also figure in generic-one sentences. Below the when-clauses restrict the agent-centered situations the implicit generic quantifier ranges over and that are also the object evaluation for the main clause:

(55) a. It is unbearable when one has just lost a parent.

b. It is like that when one is completely unprepared.

The agent-centered situations as the entities that impersonal perception reports are about relate to the shiftable context $\mathrm{c}$, just like the perceptual occurrences described by impersonal perception verbs. For the semantics of impersonal perception reports with agent-centered situations, I will assume, as is plausible, that $i t$ in subject position stands for the relevant agent-centered situation. Then the semantics in a first approximation will be as follows:

(56) Semantics of impersonal perception reports with agent-centered situations

For an impersonal perception verb $\mathrm{V}$, a modifier $\mathrm{X}$, and contexts $\mathrm{u}$ and $\mathrm{c}$, $[\text { It } \mathrm{V} \mathrm{X}]^{\mathrm{u}, \mathrm{c}}=1$ iff $\left.\exists \mathrm{d}\left(<[i t]^{\mathrm{u}, \mathrm{c}}, \mathrm{d}\right\rangle \in[\mathrm{V}]^{\mathrm{u}, \mathrm{c}} \& \mathrm{~d} \in[\mathrm{X}]^{\mathrm{u}, \mathrm{c}}\right)$, where $[i t]^{\mathrm{u}, \mathrm{c}}$ is a situation centered on $\mathrm{a}_{\mathrm{c}}$ 
There are two further observations to be made about impersonal perception reports with agent-centered situations.

First, there are cases in which the situation an (independent) impersonal perception sentence is about is in fact not the speaker-centered situation, but a contextually relevant one that one the speaker projects herself onto. These are examples:

(57) a. It looks like the TV presenter is distracted.

b. It sounds like you are exhausted.

c. There it looks like no one had cleaned up.

Putting oneself in another situation (simulating being in the center of another situation) is an option that is similarly available with generic one and impersonal verbal taste reports, when a speaker may project herself onto another agent (This tastes good when speaking to a baby).

Second, with verbs like seem and look the agent-centered situations may also be epistemic situations, constituted by the evidence that presents itself in the context:

(58) a. It seems as if there is no solution to the problem.

b. It looks as if John is innocent.

Seem and look as impersonal epistemic verbs belong to the same class as impersonal perception verbs, though of course they will not take perceptual occurrences as arguments

\section{Faultless disagreement with impersonal perception reports}

Sentences expressing judgments of personal taste are at the center of a recent philosophical debate about faultless disagreement, the possibility for two agents maintaining (59a) and (59b) respectively being both right:

(59) a. Olives are tasty.

b. Olives are not tasty.

Given my previous views, faultless disagreement is due to the sentence expressing firstperson-based genericity, involving simulation (Moltmann 2010, 2012), as below for (59a): 
(60) $\lambda x[$ Gn y taste good to(olives, $y$ qua someone $\mathrm{x}$ simulates)]

This is still a relativist account since the property in (60) needs to be self-applied by anyone accepting the content of the sentences. However, unlike standard relativist accounts, it is firstperson genericity that is crucial for explaining faultless disagreement. What matters for agreement or disagreement about taste judgments is whether agents can project themselves onto (or simulate) the same range of people on the basis of their first-person experience (or simulated experience). Two agents disagree about the taste judgments due to their ability or inability to attribute the taste judgment to anyone in the group on the basis of such identification.

Assuming first-person genericity to be the grounds for faultless disagreement, the present semantics of impersonal perception reports makes certain predictions as to when it will arise. First of all, the genericity of taste sentences with adjectival or nominal predicates is due to a taste object, not first person-based genericity. This means that with non-evaluative predicates such as bitter, sweet, unusual no faultless disagreement should arise, which appears to be correct:

(61) a. The taste of coffee is bitter.

b. This coffee is bitter.

However, a taste object may itself be subject of first-person based genericity, which arguably is part of the lexical meaning of evaluative predicates such as delicious or mediocre. With evaluative predicates, faultless disagreement clearly does arise:

(62) a. The taste of coffee is delicious.

b. Coffee is delicious.

A different prediction is made for verbal taste predicates. The genericity of verbal taste predicates is first-person-based genericity (even if the present proposal gives a more complex semantics of generic one, explicitly involving simulation). Thus verbal taste predicates should always give rise to faultless disagreement, which seems to accord with intuitions:

(63) a. This drink tastes bitter. 
b. The cake tastes unusual.

The same contrast appears to hold for other perceptual predicates:

(64) a. The perfume smells fruity.

b. The smell of the perfume is fruity.

In contrast to (64a), (64b) does not seem to give rise to faultless disagreement.

\section{Conclusion}

This paper has argued for a novel semantics of impersonal perceptual reports based on an ontology of perceptual occurrences and perceptual objects. Perceptual occurrences display the same sort of 'logophoric' first-person orientation as generic one, as do agent-centered situations as the objects of perception in impersonal perception reports with dummy subjects. 'Objective' perceptual objects are the source of genericity of perceptual reports with nominal or adjectival predicates, which is thus a distinct form of genericity from the first-person-based genericity available for perceptual reports with verbal predicates.

\section{Acknowledgments}

I would like to thank John Collins, Hazel Pearson, Matthew McGrath, Rachel Rudolph, and Dan Zeman for comments on a previous version of this paper. For very stimulating discussions, I would also like to thank the audience of an online presentation of the material of this paper at the University of Oslo in August 2021 (project S. Zobel 'Impersonal Pronouns in Norwegian, Swedish, and German').

\section{References}

Bledin, J. / S. Srinivas (to appear): 'Descriptive As Ifs'. Linguistics and Philosophy.

Chierchia, G. (1995): 'Individual Level Predicates as Inherent Generics'. In The Generic Book, ed. Gregory Carlson and Jeffry Pelletier, 176-223. Chicago, IL: University of Chicago Press.

Collins, J. (2013): 'The Syntax of Taste'. Philosophical Perspectives 27, 51-103

Dinges, A. / J. Zakkou (2020): 'Taste, traits and tendencies'. Philosophical Studies 178, 1183-1206. 
Fine, K. (2017): 'Naïve Metaphysics'. Philosophical Issues 27, edited by J. Schaffer.

Lasersohn, P. (2005), 'Context dependence, disagreement, and predicates of personal taste'. Linguistics and Philosophy 28, 643-86.

MacFarlane, J. (2014): Assessment Relativity. Relative Truth and Its Applications. Oxford UP, Oxford.

McGrath, M. (2017): 'Knowing What Things Look Like'. Philosophical Review 126, 1-41

(2018): 'Looks and perceptual justification'. Philosophy and

Phenomenological Research. 96, 110-133

(2021): 'The metaphysics of looks'. Ms Rutgers University.

Moltmann, F. (2006): 'Generic one, arbitrary PRO, and the first person'. Natural Language Semantics 14, 257-281.

(2010a): 'Generalizing detached self-reference and the semantics of generic 'one.". Mind and Language 25, 440-473.

(2010b): 'Relative truth and the first person'. Philosophical Studies 150, $187-220$.

(2012): 'Two kinds of first-person-oriented content'. Synthese 184, 157-177.

(2017): 'Cognitive Products and the Semantics of Attitude Verbs and Deontic

Modals'. In F. Moltmann / M. Textor (eds.): Act-Based Conceptions of Propositional

Content. Contemporary and Historical Perspectives. Oxford University Press, New York, 254-290.

(2018): 'An Object-Based Truthmaker Semantics for Modals'.

Philosophical Issues 28.1., 255-288.

(2019): 'Natural Language and its Ontology'. In A. Goldman / B. McLaughlin (eds): Metaphysics and Cognitive Science, Oxford UP, 206-232.

Pearson, H. (2021): 'Individual and stage-level predicates of personal taste'. To appear in J. Wyatt, J. Zakkou and D. Zeman (eds.): Perspectives on Taste. Routledge.

Rudolph, R. (to appear): 'Differences of Taste. An Investigation of Phenomenal and Non-phenomenal Appearance Sentences'. To appear in J. Wyatt, J. Zakkou and D. Zeman (eds.): Perspectives on Taste. Routledge.

Snyder, Eric. (2013): 'Binding, genericity, and predicates of personal taste'. Inquiry 56:2-3, 278-306.

Stephenson, T. (2007), 'Judge dependence, epistemic modals, and predicates of personal taste'. Linguistics and Philosophy 30: 487-525. 